\title{
INTIMATE PARTNER VIOLENCE INTERVENTIONS RELEVANT TO WOMEN DURING THE COVID-19 PANDEMIC
}

Stilwell, C., Weeks, L. E., Rothfus, M., Weeks, A., Macdonald, M., Jackson, L., Dupuis-Blanchard, S., Carson, A., Moody, E., Helpard, H., \& Daclan, A. (2021)

Full article submitted to Violence Against Women Journal

\section{THE ISSUE:}

- Violence against women/intimate partner violence (IPV) often increases during emergencies like the COVID-19 pandemic

- Public health measures that aim to slow the spread of COVID-19 increases the time isolated at home with abusers

- Physical distancing, gathering limits, and closures can create barriers for accessing and providing IPV support

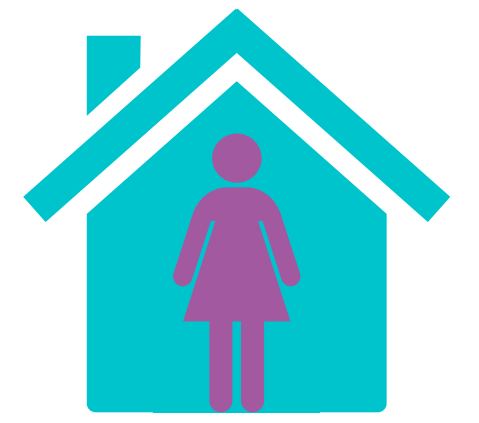

O.

\section{dy We conducted a systematic review of IPV services and interventions for women that are delivered in a way that meets COVID-19 public health guidelines}

\section{ABOUT THE IPV INTERVENTIONS INCLUDED IN THIS REVIEW:}

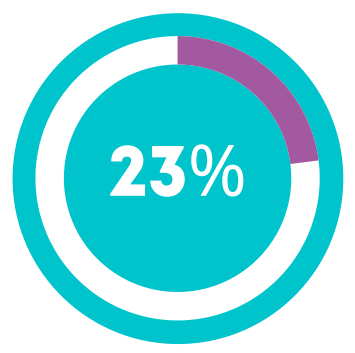

Focused on preventing IPV from occurring.
Focused on identifying IPV, recognizing IPV, and tracking/sharing information about IPV incidents.

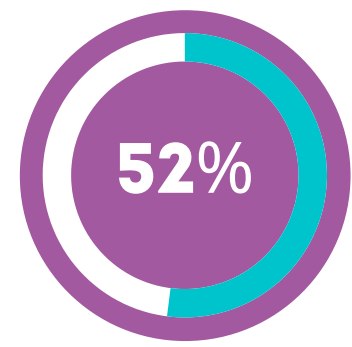

Focused on supporting women while living with and/or leaving an abusive partner.

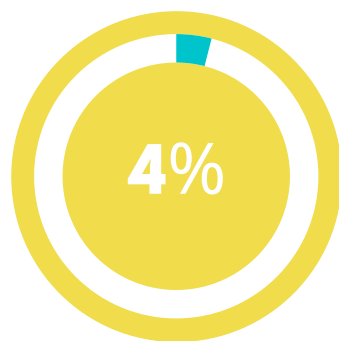

Focused on supporting women after leaving an abusive partner.

\section{A majority of studies described IPV interventions that were delivered using technology} (i.e., mHealth, telehealth, online tools, forums, emails, apps, video or phone call, and radio)

EXAMPLES OF RELEVANT IPV INTERVENTIONS:

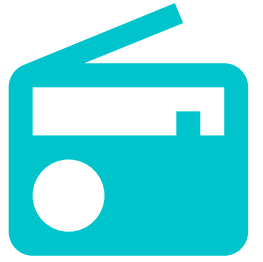

A violence/abuse awareness and education program transmitted via radio (Tanzania)

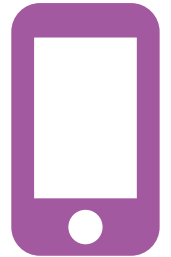

Identification and Referral to Improve Safety (IRIS), an internet-based IPV safety decision aid to flag abusive behaviours and assess safety options (USA)

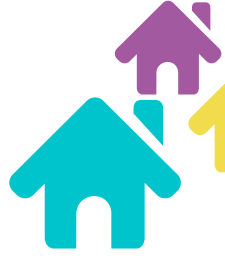

Marg's Place: an

iCanPlan4Safety online support tool to aid in risk assessment of an IPV situation and learn about options (Canada) innovative emergency

shelter model for women and children using separate smaller residences (Australia) 


\section{TECHNOLOGY IS GREAT! BUT. . .}

- SAFETY: Preventive initiatives focused on digital literacy, competence, safety, and security are essential for women to be able to confidently access online resources

- COST: Digital/virtual devices and internet connectivity can be costly: Provide resources for women to access technology and devices

- ACCESS: Advocacy is needed to ensure the stability of communication networks, especially in rural or remote areas and in low-income countries

- EFFECTIVENESS: More research and evaluation is needed to measure outcomes and effects of current IPV services and supports

- DIVERSITY: IPV intervention studies must include diverse participants and an intersectional lens. Missing crucial data on: older women; women with disabilities, immigrant/refugee women, women in the LGBTQ+community, racialized women,...

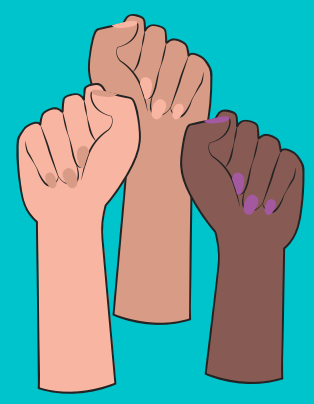

\section{INFORMATION SOURCES:}

\section{Our search found $\mathbf{2 4}$ sources that described a total of $\mathbf{2 3 8}$ interventions:}

- 4 systematic reviews ( $\mathrm{n}=218$ ) from United States, Canada, and Germany

- 20 individual studies from United States ( $n=14)$, Canada ( $n=2)$, Australia ( $n=2)$, Hong Kong ( $n=1)$, and Tanzania $(n=1)$

A full description of our methods can be found in the forthcoming article or by contacting us

\section{$\mathrm{SSHRC} \equiv \mathrm{CRSH}$}

Contact: Dr. Lori Weeks, School of Nursing, Dalhousie University Halifax, Nova Scotia Canada lori.weeks@dal.ca |1-902-494-7114

Social Sciences and Humanities Research Council of Canada Conseil de recherches en sciences humaines du Canada
DALHOUSIE UNIVERSITY

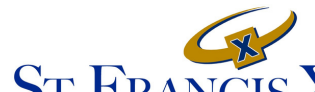

St. Francis XaVIER UNIVERSITY

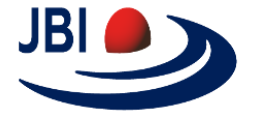

Aligning Health Needs and Evidence for Transformative Change (AH-NET-C) AJBI Centre of Excellence 